\title{
Competitive Policy Development
}

\author{
By Alexander V. Hirsch and Kenneth W. Shotts*
}

\begin{abstract}
We present a model of policy development in which competing factions have different ideologies, yet agree on certain common objectives. Policy developers can appeal to a decision maker by making productive investments to improve the quality of their proposals. These investments are specific to a given proposal, which means that policy developers can potentially obtain informal agenda power. Competition undermines this agenda power, forcing policy developers to craft policies that are better for the decision maker. This beneficial effect is strongest if policy developers have divergent ideological preferences, because their intense desire to affect policy motivates them to develop higher quality proposals. (JEL D72, D73, D78, E61)
\end{abstract}

During the early years of the New Deal, President Franklin Delano Roosevelt faced an enormous challenge. He believed that dramatic policy innovation was urgently needed on a wide range of issues, including agriculture, trade, banking, employment, and social insurance. However, although Roosevelt was well versed in policy, crafting workable proposals for such a far-reaching agenda was well beyond his capacity, or that of his immediate advisors. Instead, the president had to rely on a broader array of politicians and bureaucrats to develop new policies. Although these individuals shared some common goals (e.g., ending the Great Depression), they also had deep-seated ideological disagreements among themselves, and with the president, about what policies the federal government should pursue.

Classic and contemporary theories of bureaucratic politics would suggest that this situation was ripe for exploitation and inefficiency. Weber (1991) famously argued that the typical ruler of a modern state is reduced to being a "mere dilettante" when dealing with institutionalized bureaucratic actors. More recently, scholars building on the work of Crawford and Sobel (1982) have argued that policymaking

\footnotetext{
* Hirsch: California Institute of Technology, Division of the Humanities and Social Sciences, MC 228-77, Pasadena, CA 91125 (e-mail: avhirsch@hss.caltech.edu); Shotts: Stanford Graduate School of Business, 655 Knight Way, Stanford, CA 94305 (e-mail: kshotts@ stanford.edu). We thank Scott Ashworth, Roland Bénabou, Alex Debs, Jon Eguia, John de Figuieriedo, Catherine Hafer, Dan Kovenock, Adam Meirowitz, Christopher Stanton, and seminar audiences at Caltech, UC Irvine, Yale, the Institute for Advanced Study (Princeton), the 2013 Princeton Conference on Political Institutions and Economic Policy, the 2013 Wallis Conference on Political Economy, and the 2014 Priorat Workshop in Formal Political Science for helpful comments. We are also indebted to the editor and three anonymous referees for detailed comments and criticisms that dramatically improved both the presentation and substance of this paper. Part of Alexander Hirsch's research on this project was completed during a sabbatical at the Institute for Advanced Study (Princeton) that was partially financed by Princeton University and the Woodrow Wilson School of Public and International Affairs. The authors declare that they have no relevant or material financial interests that relate to the research described in this paper.

†o to http://dx.doi.org/10.1257/aer.20130250 to visit the article page for additional materials and author disclosure statement(s).
} 
is less effective when the experts who provide advice to a decision maker don't share his goals. However, in contrast to these theoretical expectations, historians like Schlesinger (1958) and Leuchtenburg (1963) have argued that President Roosevelt was able to induce New Deal policy developers to craft initiatives that promoted his key policy objectives. Despite some failures along the way, what resulted was one of the most active periods of policy innovation in American history, and a profound reshaping of the role of the United States government.

A major reason credited with the apparent success of policy development during the New Deal was competition within the Roosevelt administration (Schlesinger 1958). Bureaucrats and advisors who sought to influence policy in accordance with their own preferences had to contend with others who favored different approaches. In trade policy, there was intense competition between proponents of quid pro quo deals versus proponents of the most favored nation principle. In public works, there was intense competition between those who favored shovel-ready projects, those who favored development of infrastructure, and those who wanted to minimize costs. And in the area of soil conservation, the Agriculture and Interior Departments fought heatedly over control of the Forest Service, as well as over policies for mitigating the Dust Bowl.

These conflicts unsurprisingly resulted in a certain amount of pathological bureaucratic infighting. However, they also arguably generated competition to develop more effective policies. The reason was simple: anyone who wanted to convince Roosevelt to adopt a particular approach rather than competing alternatives had to produce a well-crafted policy that would also achieve the president's policy goals. For example, Schlesinger (1958, pp. 349, 535) notes that competition between Agriculture and Interior "spurred each Department to redouble its efforts in the conservation cause," and feuds over public works stimulated "more effective accomplishment" of public goals. Historians (Leuchtenburg 1963, pp. 328-29) and political scientists (Bendor 1985) have followed Schlesinger in concluding that administrative competition played a crucial role in the development of New Deal policies.

Moreover, far from being concerned about the ideological biases of his advisors, Roosevelt found it useful to draw on a wide range of sources for proposals. As he said in 1944, "You sometimes find something pretty good in the lunatic fringe. In fact, we have got as part of our social and economic government today a whole lot of things which in my boyhood were considered lunatic fringe, and yet they are now part of everyday life."1 1 Policy developers within the administration thus included Democrats, Republicans, bankers like Joseph P. Kennedy, and leftists like Harry Hopkins. In fact, the administration appeared to be "composed of human opposites put into their positions with the specific intent of generating conflict" (Gerlak and McGovern 1999, p. 70).

In this paper, we analyze the role of competition and extremism in an all-pay contest model, in which policy developers exert costly effort to improve the quality of proposals that they make to a decision maker. Contest models have been used to study lobbying (e.g., Tullock 1980; Baye, Kovenock, and Vries 1993; Che and Gale 1998), but most models focus on the allocation of a prize, rather than the adoption of a policy. Our model differs from this literature in several respects. First, the actors

${ }^{1}$ http://www.presidency.ucsb.edu/ws/?pid=16513 (accessed April 5, 2014). 
are policy-motivated, and value winning only as a means to achieve their policy goals. Second, although actors have ideological disagreements, they also have common interests, in the sense of preferring high-quality policies over low-quality ones. Finally, actors choose both the quality and the ideology of their proposals, which means that compromise can arise endogenously.

A key assumption of our model is that any quality developed to improve a policy proposal is specific to that proposal (see also Londregan 2000; Ting 2011; Hirsch and Shotts 2012). This assumption contrasts with models of endogenous acquisition of general expertise, in which an expert worries that a decision maker will expropriate her investments to achieve different policy goals (e.g., Gilligan and Krehbiel 1989). As shown by Aghion and Tirole's (1997) and Callander's (2008) models of informal authority, expertise that is non- or partially-transferable has strategic properties that are very different from general expertise. In our model, a policy developer can obtain informal agenda power by exploiting policy-specific quality to compel the decision maker to accept policies that promote her ideological interests. This setup is appropriate for analyzing effort that is strategically expended to craft a particular proposal-for example, as head of the Public Works Administration, Harold Ickes did not develop ideas for shovel-ready projects that he opposed, and instead focused on developing detailed plans for long-run infrastructure projects that he hoped would be adopted (Schlesinger 1958, pp. 281-89).

Our model generates several insights about competitive policy development. First, we show that competition always benefits the decision maker. Absent competition, a monopolistic policy developer would craft policies that promote her interests without providing much benefit to the decision maker. Competition serves to discipline policy developers, forcing them to craft policies that are closer to the decision maker's ideal point, and often higher quality.

Second, we assess a natural intuition: that a decision maker would prefer policy developers whose ideologies are closely aligned with his own, to ensure that they develop policies in line with his own preferences. However, consistent with the experience of the Roosevelt administration, we show that it is actually better to have competing policy developers with divergent preferences, whose intense desire to affect policy motivates them to exert effort to develop high-quality proposals.

Finally, we show that although the decision maker, ceteris paribus, prefers moderate policies, the model generates endogenous extremism of policy choices and outcomes. That is, the decision maker benefits from extreme policy proposals, and chooses them over moderate ones. This happens because quality is endogenous, and a policy developer who makes an extreme proposal will exert sufficient effort improving its quality to overcompensate the decision maker for his ideological losses. Our model thus provides an account for why extremist policy developers may be present in the policymaking arena, successful in getting their policies enacted, and beneficial for moderates.

\section{The Model}

Two entrepreneurs, left and right $(L, R)$, develop competing policies for consideration by a decision maker $(D)$. A policy $(y, q)$ consists of an ideology $y \in \mathbb{R}$ and a level of quality $q \in[0, \infty)=\mathbb{R}^{+}$. The ideology dimension captures any aspect of 
policy over which players disagree, which could be classical left-right political ideology but also distributional considerations such as organizational "turf." The quality dimension captures policy features valued by all players, such as cost savings, efficient administration, or economic growth. All players care about the ideology and quality of the policy that is ultimately chosen, an assumption that differs from most previous contest models, in which participants' utility for losing the contest is fixed (e.g., Siegel 2009). Utility functions take the form $U_{i}(y, q)=q-\left(x_{i}-y\right)^{2}$, where $x_{i}$ is player $i$ 's ideological ideal point. The decision maker's ideal point is normalized to be $x_{D}=0$, and the entrepreneurs are on either side $\left(x_{L}<0\right.$ and $\left.x_{R}>0\right)$.

The game has two stages. In the policy development stage, the entrepreneurs simultaneously craft policies $\left(y_{i}, q_{i}\right)$. Producing quality $q_{i}$ on a policy with ideology $y_{i} \operatorname{costs} c_{i}\left(q_{i}\right)=\alpha_{i} q_{i}$ up-front, reflecting the investment of time and resources required to develop a well-designed policy proposal. For simplicity, the marginal cost of generating quality is constant, independent of ideology, and greater than the marginal benefit $\left(\alpha_{i}>1\right)$.

In the policy choice stage, the decision maker chooses one of the two new policies or a reservation policy. This is assumed to be $(0,0)$, capturing the idea that the decision maker lacks policy-development capacity, and so will simply select a poorly designed policy that reflects his ideological preferences. The decision maker also cannot transfer quality generated for one policy to another policy; in the terminology of Hirsch and Shotts (2012) it is policy-specific. For example, if an entrepreneur invests time and effort to develop an effective and equitable school voucher program, the decision maker cannot expropriate those investments to develop an alternative policy that improves the quality of public schools.

For most of the analysis, we consider a symmetric variant in which the entrepreneurs are equally extreme $\left(\left|x_{L}\right|=x_{R}=x\right)$ and equally skilled at developing quality $\left(\alpha_{L}=\alpha_{R}=\alpha\right)$. The parameter $x$ represents the extremism of ideological interests in the policymaking arena relative to the decision maker, and $\alpha$ captures the efficiency of the technology for generating high-quality policies.

\section{A. Preliminaries}

Absent competition, our model is similar to Snyder's (1991) model of vote-buying without price discrimination. A policy "monopolist" develops a policy that balances the marginal ideological benefit of moving policy in her direction against the marginal cost of producing just enough quality to obtain the decision maker's approval. ${ }^{2}$ The decision maker is left no better off than with the reservation policy, because the monopolist extracts all the benefits of quality in the form of ideological rents.

With competition, the model is a variant of an all-pay contest (Siegel 2009), with some distinctive properties that we highlight later. As in Che and Gale (2003), bids $\left(y_{i}, q_{i}\right)$ are two-dimensional, and there is a score function $s\left(y_{i}, q_{i}\right)$ determining the winner. In our model, a policy's score is the utility it provides to the decision maker $s(y, q)=U_{D}(y, q)=q-y^{2}$, because the decision maker cannot commit in advance to which policy he will choose.

\footnotetext{
${ }^{2}$ See also Hitt, Volden, and Wiseman's (2014) analysis of legislative effectiveness.
} 
For most of the analysis, we rewrite strategies and utilities in terms of the score. With this transformation, an entrepreneur effectively chooses a target level of utility $s_{i}$ to offer to the decision maker, and a combination of ideology $y_{i}$ and quality $q_{i}=s_{i}+y_{i}^{2}$ to achieve that target. Quality costs $\alpha_{i}\left(s_{i}+y_{i}^{2}\right)$ to produce, so more ideologically extreme policies-while better for the entrepreneur in the event of adoption-are more costly up-front because they require greater investments in quality to achieve the same utility for the decision maker.

In Lemma 1 in the online Appendix, we show that all equilibria satisfy intuitive conditions. Each entrepreneur $i$ 's strategy can be described by two components: a univariate cumulative distribution funtion $(\mathrm{CDF}) F_{i}\left(s_{i}\right)$ over scores, and a unique ideology $y_{i}\left(s_{i}\right)$ for each score $s_{i}>0$, capturing how she trades off quality investments and ideological demands. The entrepreneurs mix smoothly over a common non-empty interval of scores $[0, \bar{s}]$, so there are no atoms or ties. Finally, at least one entrepreneur $k$ is always active, in the sense of developing a policy that is strictly better for the decision maker than the reservation policy $\left(F_{k}(0)=0\right)$. Using these properties, we now heuristically derive the equilibrium strategies and results. Technical details are in the online Appendix..$^{3}$

\section{B. Optimal Ideologies}

An entrepreneur's utility from a policy with score $s$ and ideology $y$ is $V_{i}(s, y)$ $=U_{i}\left(y, s+y^{2}\right)=-x_{i}^{2}+s+2 x_{i} y$. This is linearly increasing in score holding ideology fixed, and it is also linear in ideological movements holding score fixed; that is, moving along the decision maker's indifference curves. Entrepreneur $i$ 's utility for developing a policy $\left(s_{i}, y_{i}\right)$ with score $s_{i}>0$ is

$$
\begin{aligned}
\Pi_{i}\left(s_{i}, y_{i} ; F_{-i}(\cdot), y_{-i}(\cdot)\right)= & -\alpha_{i}\left(s_{i}+y_{i}^{2}\right)+F_{-i}\left(s_{i}\right) \cdot V_{i}\left(s_{i}, y_{i}\right) \\
& +\int_{s_{i}}^{\infty} V_{i}\left(s_{-i}, y_{-i}\left(s_{-i}\right)\right) d F_{-i} .
\end{aligned}
$$

The first term is the up-front cost of producing quality, and the second is the probability of victory multiplied by the policy payoff. The third term is $i$ 's policy utility when losing.

We note two properties of equation (1) that arise from our assumptions that the entrepreneurs invest in quality, and are purely policy-motivated. First, unlike Che and Gale (2003), there is no pure all-pay component of the strategies. Quality has a marginal up-front cost of $\alpha_{i}$, but with probability $F_{-i}\left(s_{i}\right)$ the policy is adopted and yields an intrinsic marginal benefit of 1 . This means that the entrepreneurs are more willing to invest in improving the quality of policies that are more likely to be adopted, because they are also more likely to enjoy the intrinsic benefits. Second, because an entrepreneur cares about policy, rather than winning per se, calculating her utility when she loses requires integrating over all the endogenous policies $\left(s_{-i}, y_{-i}\left(s_{-i}\right)\right)$ in her opponent's strategy that would defeat her own. Thus, there are rank-order spillovers (Baye, Kovenock, and Vries 2012), in the sense that the winner's strategy has a direct effect on the loser's utility.

\footnotetext{
${ }^{3}$ The equilibrium concept is subgame perfect Nash. We restrict attention to equilibria in which the players use strategies that are the sum of an absolutely continuous and a discrete distribution.
} 
We now characterize an entrepreneur's optimal combination of ideology and quality at every score. The key simplification is that holding the probability of winning (i.e., score) fixed, $i$ 's policy only affects her utility when she wins, and her opponent's policy only affects her utility when she loses. Thus, the only aspect of $-i$ 's strategy that affects $i$ 's optimal combination of ideology and quality at score $s_{i}$ is the probability $F_{-i}\left(s_{i}\right)$ that $-i$ develops a lower-score policy, which is equal to the probability that $i$ 's policy wins. Taking the first-order condition of equation (1) with respect to $y_{i}$ then yields the optimal policy at each score.

\section{OBSERVATION 1: With probability 1 an entrepreneur's policies $\left(s_{i}, y_{i}\right)$ are either} 0 -quality and never win, or satisfy $y_{i}=y_{i}^{*}\left(s_{i}\right)=\left(\frac{x_{i}}{\alpha_{i}}\right) F_{-i}\left(s_{i}\right)$.

Note that the observation relies on properties of the equilibrium score CDFs-in particular, the absence of atoms above 0 and the fact that one entrepreneur is always active - that are proven in Lemma 1 in the online Appendix.

Observation 1 yields several insights about the connection between ideology and quality when both are chosen by strategic actors. First, more ideologically extreme entrepreneurs produce more ideologically extreme policies ceteris paribus, because they are more willing to pay the sure costs of developing quality for the uncertain benefits of ideological gains. Second, more skilled entrepreneurs (i.e., lower $\alpha_{i}$ ) also produce more extreme policies ceteris paribus, because they are better able to generate quality and exploit it to realize ideological gains. Finally, more ideologically extreme policies in the support of an entrepreneur's strategy are not just higher quality - they are also strictly better for the decision maker, and more likely to be adopted. The entrepreneurs therefore overcompensate the decision maker for his ideological losses when they develop more extreme policies.

The equilibrium association between extremism, quality, and decision maker utility is counterintuitive, but it emerges naturally from the entrepreneurs' incentives. Policies $\left(s_{i}, y_{i}\right)$ that are better for the decision maker have a higher probability $F_{-i}\left(s_{i}\right)$ of adoption, so an entrepreneur is more willing to pay the certain quality costs of proposing a more extreme ideology in exchange for the uncertain ideological gains in the event of victory.

\section{Equilibrium Score Conditions}

To derive the equilibrium score CDFs $\left(F_{i}, F_{-i}\right)$, note that every score $s_{i} \in[0, \bar{s}]$ in the common support of the entrepreneurs' score CDFs must maximize $i$ 's utility when the optimal policies $y_{i}^{*}(s)$ are developed: i.e., with probability $1 i$ chooses a $s_{i} \in \arg \max _{s_{i}}\left\{\Pi_{i}\left(s_{i}, y_{i}^{*}\left(s_{i}\right) ; F_{-i}(\cdot), y_{-i}^{*}(\cdot)\right)\right\}$. Since $i$ is indifferent over all scores in $[0, \bar{s}]$, differentiating $\Pi_{i}\left(s_{i}, y_{i}^{*}\left(s_{i}\right) ; F_{-i}(\cdot), y_{-i}^{*}(\cdot)\right)$ with respect to $s_{i}$ and setting it equal to zero yields a pair of differential equations that must be jointly satisfied in equilibrium,

$$
\begin{gathered}
\alpha_{i}-F_{-i}(s) \cdot 1=f_{-i}(s) \cdot 2 x_{i}\left(\left(\frac{x_{i}}{\alpha_{i}}\right) F_{-i}(s)-\left(\frac{x_{-i}}{\alpha_{-i}}\right) F_{i}(s)\right) \\
\forall s \in[0, \bar{s}] \text { and } i \in\{L, R\} .
\end{gathered}
$$


Equation (2) has a natural interpretation. The left side is $i$ 's net marginal cost of increasing the score she offers: she pays $\alpha_{i}>1$ to generate additional quality, but with probability $F_{-i}(s)$ she wins and enjoys the marginal benefit, 1, of that additional quality. The right side is $i$ 's marginal ideological gain from increasing her score: with probability $f_{-i}(s)$ she goes from losing to winning the contest, which shifts the outcome from $y_{-i}^{*}(s)=\left(\frac{x_{-i}}{\alpha_{-i}}\right) F_{i}(s)$ to $y_{i}^{*}(s)=\left(\frac{x_{i}}{\alpha_{i}}\right) F_{-i}(s)$.

Notably, the entrepreneurs' policy motivation and the resulting rank-order spillovers induce a mutual dependence between the equilibrium score CDFs. The reason is that entrepreneur i's score CDF directly affects the ideology of her opponent's policy at each score. In particular, if $i$ starts to drop out of the contest (a higher $F_{i}(s)$ ), her opponent's equilibrium response is to be more ideologically aggressive (a more extreme $y_{-i}^{*}(s)$ ). Because $i$ is policy-motivated, this increases the harm to her of dropping out. The entrepreneurs' policy motivation thus magnifies the intensity of competition in the model.

\section{Equilibrium of the Symmetric Model}

We now heuristically derive the unique equilibrium of the symmetric model; details are in the proof of Proposition 1. The equilibrium involves a common score CDF $F(s)$ satisfying $F(0)=0$, i.e., both entrepreneurs are always active. Applying symmetry to equation (2), we then obtain the single differential equation $\alpha-F(s)=f(s) \cdot 4 \frac{x^{2}}{\alpha} F(s)$. A simpler equation may be derived on the inverse $F^{-1}(F)$ by substituting in $F^{-1}(F)$ for $s$ and observing that $\frac{1}{f\left(F^{-1}(F)\right)}=\frac{\partial}{\partial F}\left(F^{-1}(F)\right)$,
which produces

$$
\frac{\partial}{\partial F}\left(F^{-1}(F)\right)=4 x^{2}\left(\frac{F / \alpha}{\alpha-F}\right)
$$

Solving and applying the boundary condition $F(0)=0 \Leftrightarrow F^{-1}(0)=0$ (i.e., both entrepreneurs are always active) then yields the unique equilibrium.

PROPOSITION 1: The inverse of the common equilibrium score CDF in the symmetric model is $F^{-1}(F)=4 x^{2}\left(\ln \left(\frac{\alpha}{\alpha-F}\right)-\frac{F}{\alpha}\right)$, and equilibrium proposal ideologies are $y_{i}(s)=\operatorname{sign}\left(x_{i}\right) \cdot \frac{x}{\alpha} F(s)$.

The equilibrium can be expressed more intuitively in terms of a common probability distribution $G(y)$ over the ideological extremism of entrepreneurs' proposals, and a function $s(y)$ that maps the ideological extremism of each policy to its score (recall that the quality $q(y)$ of a policy with ideological extremism $y$ is $s(y)+y^{2}$ ). From Observation 1, $y(s)=\frac{x}{\alpha} F(s) \Leftrightarrow s(y)=F^{-1}\left(\frac{y}{x / \alpha}\right)$. To derive $G(y)$, observe that the probability that an entrepreneur develops a policy less extreme than $y$ is also the probability $F(s(y))$ that she develops a lower-score policy, $F\left(F^{-1}\left(\frac{y}{x / \alpha}\right)\right)$ $=\frac{y}{x / \alpha}$. We thus obtain the following result. 
COROLLARY 1: In equilibrium, the ideological extremism of the entrepreneurs' policies is uniformly distributed over $\left[0, \frac{x}{\alpha}\right]$, and the score $s(y)$ of a policy with extremism $y$ is $4 x\left(x \ln \left(\frac{x}{x-y}\right)-y\right)$.

\section{Equilibrium Properties}

The equilibrium strategies of the competitive symmetric model are illustrated in Figure 1 in ideology-quality space. For purposes of comparison, the figure also shows the monopoly policy that each entrepreneur would develop absent competition. In the competitive equilibrium, the entrepreneurs mix smoothly over developing policies located on two symmetric curves that extend from $(0,0)$ out to $\left( \pm \frac{x}{\alpha}, \bar{s}+\left(\frac{x}{\alpha}\right)^{2}\right)$. The distribution of each entrepreneur's policies projected onto the ideology $(x)$-axis is uniform.

\section{A. Benefits of Competition}

As a monopolist, each entrepreneur would produce a noncentrist policy with just enough quality to make the decision maker indifferent with the reservation policy. Competition forces the entrepreneurs to moderate the ideology of their proposals. Although they do not always produce policies that are higher quality than the monopoly policy, their proposals are always strictly better for the decision maker. Thus, the decision maker always benefits from competition. This result contrasts with Rotemberg and Saloner's (1994) argument that firms benefit from narrowing their focus and eliminating internal competition. A key difference is that entrepreneurs in our model care about the policy outcome even if they lose, which intensifies productive competition.

\section{B. Endogenous Extremism}

A property of equilibrium is that the decision maker always chooses the more ideologically extreme proposal: in Figure 1, more-extreme proposals are located on higher decision maker indifference (i.e., score) curves. The decision maker's preference for policies on the "lunatic fringe" emerges endogenously from the entrepreneurs' strategic incentives to invest in quality. Because they are only interested in influencing outcomes, entrepreneurs never develop an extreme policy unless they also make the up-front investments necessary to give it a high chance of success (see Observation 1).

While this prediction is no doubt unusual, it is important to recall that policy entrepreneurs in the real world may propose extreme policies for reasons other than a desire to influence outcomes. For example, they may engage in position-taking, i.e., making proposals that are unlikely to succeed, in order to please certain constituencies. Or, they may have intrinsic preferences over their policy proposals irrespective of the outcome. These factors would make it more difficult to observe our prediction in real-world policymaking. At a minimum, however, our model shows that empirical studies should take into account how strategic actors endogenously affect difficult-to-observe features of the policies that they propose (Triossi, Valdivieso, and Villena-Roldán 2014). 


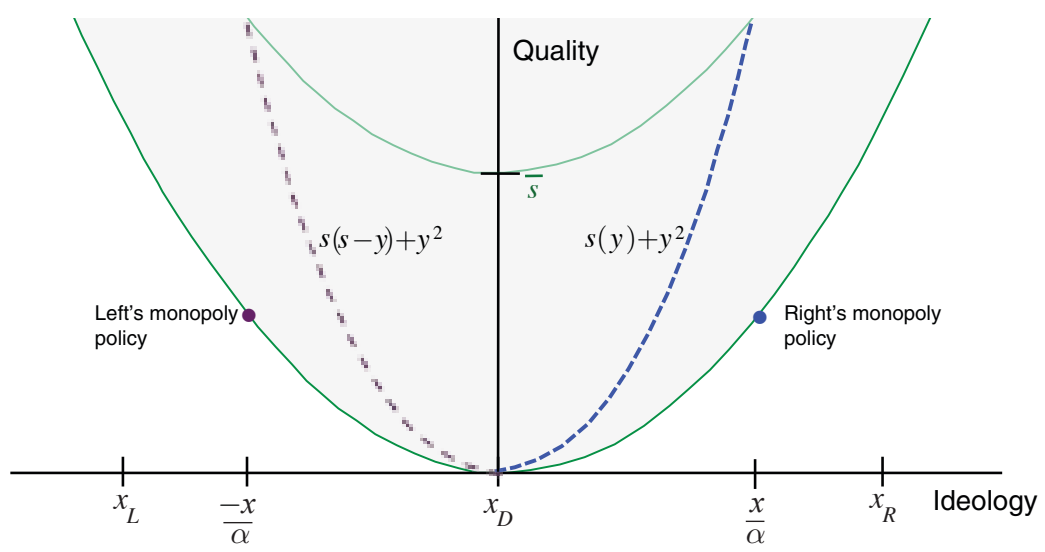

Figure 1. Equilibrium Strategies in the Symmetric Model

\begin{abstract}
Notes: Each entrepreneur produces policies with ideologies uniformly distributed over the interval $\left[0, \pm \frac{x}{\alpha}\right]$. The dashed curves represent the policies that the entrepreneurs produce at each ideological location in the support of their strategies. In equilibrium, the entrepreneurs' policies generate utilities for the decision maker (scores) that lie on a common interval $[0, \bar{s}]$. The monopoly policy that each would produce absent competition is depicted as a dot on the decision maker's score curve for $s=0$.
\end{abstract}

The decision maker's endogenous preference for extreme policies also generates equilibrium polarization in policy outcomes. As shown in Figure 2, more-extreme policies have higher density than less-extreme ones within the interval $\left[-\frac{x}{\alpha}, \frac{x}{\alpha}\right]$. While polarization is often perceived as being a sign of political dysfunction, in our model it arises from ideologically motivated actors' productive engagement in the policy process.

\title{
C. Comparative Statics
}

The consequences of having more ideologically extreme (higher $x$ ) and/or more skilled (lower $\alpha$ ) entrepreneurs are simple to derive from the CDF over ideology $G(y)=\frac{y}{x / \alpha}$, the inverse CDF over score $F^{-1}(F)$ from Proposition 1, and the inverse $\operatorname{CDF} H^{-1}(H)$ over quality, which is equal to $F^{-1}(H)+\left(H \frac{x}{\alpha}\right)^{2}$ because $q(y)=s(y)+y^{2} 4^{4}$

PROPOSITION 2: As the entrepreneurs become more extreme (higher $x$ ) or more skilled (lower $\alpha$ ), their proposals become first-order stochastically more extreme, but also first-order stochastically higher quality and better for the decision maker.

Polarized entrepreneurs naturally produce ideologically extreme policies. However, as the entrepreneurs become more polarized their disagreement actually benefits the decision maker, because they invest more in quality. They have two reasons for doing this. First, they care more intensely about ideological gains. Second,

\footnotetext{
${ }^{4}$ The decision maker's equilibrium utility is $\int_{0}^{\bar{s}} \frac{\partial}{\partial s}\left([F(s)]^{2}\right) s \cdot d s=\int_{0}^{1} \frac{\partial}{\partial F}\left(F^{2}\right) F^{-1}(F) \cdot d F$.
} 


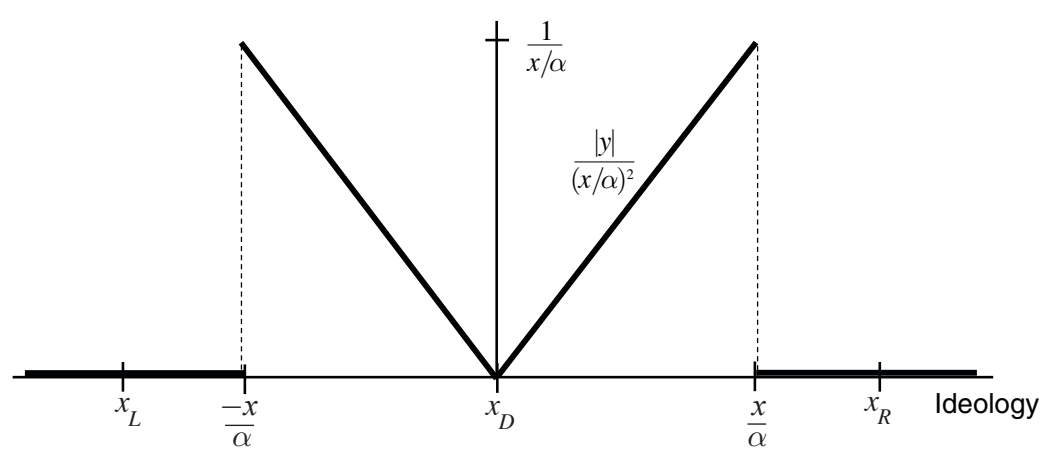

Figure 2. Density of Ideological Outcome

Note: The density of the final ideological outcome resulting from the competitive symmetric equilibrium, which is $\frac{|y|}{(x / \alpha)^{2}}$ within the interval $\left[-\frac{x}{\alpha}, \frac{x}{\alpha}\right]$ and 0 elsewhere.

each entrepreneur wants to prevent the other's increasingly extreme policies from being adopted.

The effect of increasing the entrepreneurs' skill is actually similar to the effect of ideological polarization. Entrepreneurs who are better able to generate high-quality policies attempt to exploit that ability to achieve ideological gains, which results in extreme policy proposals, but also benefits the decision maker. Thus, an increase in observed policy extremism may occur as a by-product of greater skill at policy development, and does not necessarily indicate that actors with centrist preferences are worse off.

\section{Entrepreneurs' Utility}

So far we have focused on how competitive policy development affects the decision maker, showing that he chooses more extreme (endogenous) policies over less extreme ones, benefits from competition, and prefers to have more skilled entrepreneurs despite the greater policy extremism that results. We now turn to the entrepreneurs, and show that these results do not, in general, extend to them.

First, for reasonable values of the cost parameter $(\alpha \geq 3)$ each entrepreneur prefers the moderate policies within the support of her opponent's strategy, since the additional quality of extreme ones is insufficient to compensate for her ideological losses. Thus, disagreement between the entrepreneurs endures even after they have made common-value investments in their respective policies.

Second, each entrepreneur is always harmed by the presence of a competitor. ${ }^{5}$ In addition, for most values of $\alpha(>\bar{\alpha} \approx 1.23)$ the entrepreneurs would prefer to jointly give up policy development capacity and allow the decision maker to choose the reservation policy. The decision maker is thus the main beneficiary of competitive policy development, even though the entrepreneurs make common-value investments. This feature is shared with common agency models of influence (Dixit,

\footnotetext{
${ }^{5}$ The entrepreneurs' equilibrium utility is $\Pi_{i}^{*}(\bar{s} ; F)=-\alpha\left(\bar{s}+(x / \alpha)^{2}\right)+V_{i}\left(\bar{s}, x_{i} / \alpha\right)=-(1-1 / \alpha) x^{2}-$ $(\alpha-1) \bar{s}$, i.e., their utility from producing score $\bar{s}=F^{-1}(1)$ with ideology $\pm \frac{x}{\alpha}$ and winning for sure.
} 
Grossman, and Helpman 1997), where equal and opposing interest groups are hurt by competition because influence is costly and policy is unchanged.

Finally, for $\alpha>\hat{\alpha} \approx 2.11$ the entrepreneurs are harmed by shared improvements in their skill at policy development, because of the greater ideological extremism of their policies, as well as the more intense competition over quality. We summarize these observations below.

PROPOSITION 3: The entrepreneurs (i) prefer their opponents' more moderate equilibrium policies to their more extreme ones when $\alpha \geq 3$, (ii) prefer being a monopolist to facing competition, (iii) prefer the reservation policy to the competitive equilibrium when $\alpha>\bar{\alpha}>1$, and (iv) prefer higher (common) costs of developing quality when $\alpha>\hat{\alpha}>\bar{\alpha}$.

Only when $\alpha \in(1, \bar{\alpha})$, i.e., when the entrepreneurs come sufficiently close to valuing quality for its own sake, do they benefit both from their joint ability to develop policies, and from further improvements in their skill.

\section{Additional Questions}

Overall, our model paints a picture of vigorous engagement by ideological extremists in a competitive policy environment, a pattern that is consistent with prior contest-theoretic models of social conflict (e.g., Esteban and Ray 1999). Unlike previous work, however, the key vehicle for competition is productive investments in quality, which are strategically useful because they are valued by a decision maker who freely chooses which policy to implement. Consequently, competition benefits the decision maker despite observably extreme ideological outcomes. In addition, the decision maker benefits from increasingly polarized policy developers.

We now discuss several variants of our model, to better understand these results and assess their robustness. We first consider alternative assumptions about the set of entrepreneurs, to see whether centrists are likely to be active in addition to, or instead of, the two extremists in our model. We next consider alternative assumptions about the entrepreneurs' utilities and strategies, analyzing what happens if they disagree about "quality," if they can sabotage each other's policies, or if they are dogmatically unwilling to compromise. ${ }^{6}$

\section{A. An Entrepreneur Aligned with the Decision Maker}

In our model, the decision maker is assumed to lack policy-development capacity. However, some political leaders have direct subordinates who share their goals, as well as close allies that they could invite to develop policy proposals. A natural intuition is that the decision maker in our model would benefit if one of the extremist entrepreneurs were replaced by a centrist. In fact, the reverse is true: competition

\footnotetext{
${ }^{6}$ In related work (Hirsch and Shotts 2014b) we also consider the effects of granting veto rights to noncentrists, which is a common consequence of separation of powers and supermajority rules (Krehbiel 1998). We show that veto players' resistance to change can encourage policy developers to make even greater investments in quality. However, veto players who are too extreme instead induce harmful policy gridlock.
} 
vanishes, the remaining extremist behaves as a monopolist, and the decision maker is no better off than with the reservation policy.

PROPOSITION 4: Fix $x_{L}<0$ and $\alpha_{L}>1$. If $R$ is centrist $\left(x_{R}=x_{D}=0\right)$ and has any level of skill $\left(\alpha_{R}>1\right)$, the unique equilibrium is as if she were absent. The left entrepreneur develops her monopoly policy, the right entrepreneur does nothing, and the decision maker is no better off than with the reservation policy.

The reason for this result is simple: in our model, productive investments are inspired by the prospect of ideological gains. A centrist entrepreneur's ideological interests are already protected by the decision maker, so to her, the left entrepreneur's policies are equivalent to centrist policies with quality $s_{L}$. Her cost of developing higher-quality centrist policies $\alpha_{R} s_{R}$ outweighs the benefit $s_{R}-s_{L}$, so she remains inactive.

\section{B. Additional Entrepreneurs}

In many policymaking environments, multiple actors could choose to enter the fray and develop new policies. We now consider what happens when additional moderate entrepreneurs are introduced between the two extremists in our model.

PROPOSITION 5: The equilibrium with two symmetric entrepreneurs $\left|x_{L}\right|$ $=x_{R}=x$ and common costs $\alpha$ remains an equilibrium when $N$ weakly more-moderate $\left(\left|x_{j}\right| \leq x\right)$ and less-skilled $\left(\alpha_{j} \geq \alpha\right)$ entrepreneurs are present. In this equilibrium, the additional entrepreneurs are inactive.

When additional entrepreneurs are present who are (weakly) more moderate and no more skilled than the existing extremists, there always exists an equilibrium in which the more-moderate entrepreneurs allow two extremists to shoulder the burden of policy development. ${ }^{7}$ Compared to them, a moderate has less to gain from engaging in the policy contest: she values ideological gains less, and already benefits from an aligned extremist's participation. This suggests a tendency for individuals with more extreme ideological preferences to dominate policy contests.

\section{Entrepreneurs Who Discount the Quality of Each Other's Policies}

In some political environments, there are nonpolicy costs to the losing faction that increase with the quality of the winning policy: for example, the winning faction's strength may increase in future electoral, legislative, or bureaucratic contests. Moreover, "quality" may have very different meanings for factions on opposite sides of the political spectrum. ${ }^{8}$ For example, a teachers' union may prefer that a voucher

\footnotetext{
${ }^{7}$ We do not rule out other equilibria. However, the equilibrium with two active extremists is unique if the additional entrepreneurs are at $x_{D}=0$.

${ }^{8}$ However, Kendall, Nannicini, and Trebbi's (2015) study of Italian voters suggests that some voters don't discount the quality of ideologically distant policies or candidates.
} 
system be inefficient, cumbersome, and unreliable, because this would deter parents from pulling their children out of the public schools.

As a reduced form for analyzing such considerations, we check whether our results are robust to assuming that each entrepreneur places a lower, zero, or even negative value on the quality of her opponent's policies. Suppose each entrepreneur $i$ values the quality of her opponent's policies at $(1-\beta) q_{-i}$, where $\beta \geq 0$, so that $i$ 's payoff from - $i$ 's policy is $V_{i}\left(s_{-i}, y_{-i}\right)-\beta\left(s_{-i}+y_{-i}^{2}\right)$. With this setup, each entrepreneur effectively faces a higher cost of losing the contest. Solving this variant of our model yields the following results.

PROPOSITION 6: For all $\beta \geq 0$ there is a unique symmetric equilibrium in which (i) the ideology of equilibrium policies is the same as in the baseline model, (ii) Proposition 2 holds, (iii) the quality and score of the entrepreneurs'policies and the final policy outcome are first-order stochastically increasing in $\beta$, and (iv) the marginal effect of extremism $x$ on the decision maker's utility is increasing in $\beta .{ }^{9}$

This proposition shows that our main results are actually strengthened when entrepreneurs discount each other's quality. Policy outcomes are no more ideologically extreme, but are higher quality. Moreover, the benefits of extremism are stronger, in the sense that the marginal benefit to the decision maker of greater polarization is higher. These effects arise for the same reasons as our main results: the entrepreneurs' dislike of each other's policies, whether for ideological or "quality" reasons, is funneled into productive investments.

\section{Sabotage}

An additional potential concern with our model is that real-world competition isn't always productive; political factions sometimes interfere with policy implementation or engage in other forms of sabotage to shift policy decisions in their favor. Although a complete analysis of sabotage is beyond the scope of our paper, ${ }^{10}$ we briefly comment on why we believe it is reasonable to expect costly political activity to focus on productive investments.

Consider a variant of our model in which each entrepreneur $i$ can also pay an up-front $\operatorname{cost} \alpha_{i}^{s} q_{i}^{s}$ to engage in sabotage and thereby reduce the quality of her opponent's policy by $q_{i}^{s}$. If each entrepreneur uses a combination of productive investment and sabotage, then the decision maker prefers $i$ 's proposal over $-i$ 's proposal if and only if $\left(q_{i}-q_{-i}^{s}\right)-y_{i}^{2} \geq\left(q_{-i}-q_{i}^{s}\right)-y_{-i}^{2}$. Rearranging, this is equivalent to the decision maker's utility from $i$ 's policy $q_{i}-y_{i}^{2}$, plus $i$ 's level of sabotage $q_{i}^{s}$, exceeding that of her opponent.

What combination of investment $q_{i}$ and sabotage $q_{i}^{s}$ will entrepreneur $i$ use? Clearly, if $i$ engages in sabotage and fails to win, then she is worse off because her sabotage reduces the quality of the actual policy outcome. Less obvious, however, is the fact that using sabotage also harms $i$ when she wins, because it redirects her

\footnotetext{
${ }^{9}$ Note that we do not assert for this variant that all equilibria are symmetric.

${ }^{10}$ In particular, it is an open question whether the decision maker benefits from extremism of entrepreneurs in equilibria that involve a combination of sabotage and productive investment.
} 
effort away from productive investment. Thus, it can be shown that sabotage will only disrupt the equilibrium in Proposition 1 if its marginal cost is sufficiently lower than the marginal cost of investing in quality, i.e., $\alpha_{i}^{s}<\alpha_{i}-1$. Only when this condition holds is sabotage sufficiently cheap to compensate the entrepreneur for both the harm she does to her opponent's policy, and the foregone value of investing in her own policy's quality. ${ }^{11}$

Note that this analysis uses our baseline assumption that entrepreneurs fully value quality even when they lose. However, because sabotage is more appealing for entrepreneurs who don't value each other's quality, we generalize the analysis to cover that case as well.

PROPOSITION 7: If entrepreneur $i$ values $-i$ 's quality at $(1-\beta) q_{-i}$ there exists an equilibrium without sabotage if and only if $\alpha^{s} \geq \alpha-(1-\beta)$.

Discounting an opponent's quality thus increases the range of $\alpha^{s}$ where sabotage must occur. Nevertheless, as long as the entrepreneurs place some positive weight on each other's quality, sabotage can be absent even when it is strictly cheaper than investing in quality. ${ }^{12}$

\section{E. Dogmatic Entrepreneurs}

A final issue we consider has to with the fact that the entrepreneurs in the model are risk-averse over ideology. This implies that, compared to moderates, extremists place a higher value on small shifts away from the reservation policy, and thus are more willing to invest in quality to achieve ideological gains. Although risk aversion is a standard assumption in the literature, it cannot capture the preferences of one type of political extremist: someone who only values policy done her way, and therefore places little or no weight on gains achieved via compromise.

We now consider how dogmatic, risk-loving entrepreneurs would influence our results. Suppose for simplicity that each entrepreneur's utility function takes the form $U_{i}(y, q)=q+1_{y=x_{i}} \cdot B\left|x_{i}\right|$ where $B \geq 0$, so that she receives a net benefit of $B\left|x_{i}\right|$ whenever her ideal policy is chosen, but is indifferent over all other ideological outcomes. As in our baseline model, each entrepreneur's benefit from getting her ideal is increasing in her extremism. But unlike our baseline model, she only values her ideal ideological outcome and thus is strongly risk-loving. The preferences of the decision maker remain unchanged.

In contrast to our main model, a dogmatic entrepreneur will only develop positive-score policies at her own ideal point, because she doesn't value compromise victories. Thus each entrepreneur's $F_{i}(0)$ must be sufficiently high to make her opponent $-i$ willing to develop a proposal at $x_{-i}$ with quality $q_{-i} \geq x_{-i}^{2}$. Conditional on developing a proposal, each entrepreneur mixes over a range of positive scores.

\footnotetext{
${ }^{11}$ Konrad (2000) shows that sabotage often is not an optimal strategy in multiplayer rent-seeking contests; our analysis differs because we consider only two players, and quality investments are directly productive.

${ }^{12}$ Similarly, if sabotage only makes the policy less appealing to the decision maker (e.g., if it is negative campaigning) then an equilibrium with no sabotage exists if and only if $\alpha^{s} \geq \alpha$.
} 
The following proposition analyzes equilibria, including the one that is decision maker-optimal.

PROPOSITION 8: With dogmatic entrepreneurs, there exists an equilibrium in which the decision maker's utility is strictly positive if and only if $x \in\left(0, \frac{B}{\alpha-1}\right)$. The online Appendix characterizes a symmetric equilibrium in which decision maker utility is ( $i)$ weakly greater than in any other equilibrium, (ii) continuous, and (iii) strictly quasiconcave over $x \in\left[0, \frac{B}{\alpha-1}\right]$.

Thus, when the entrepreneurs have uncompromising preferences, it is no longer true that more polarization always benefits the decision maker. Instead, extremism is only good up to a point. It can spur investments in quality, but eventually the entrepreneurs' cost of compensating the decision maker for their ideal policies becomes so high that they drop out of the contest.

Note that developing a 0 -quality extreme policy in lieu of the reservation policy is also consistent with equilibrium: such a policy is free, will never be adopted, and so is effectively 0 -score. "Inactivity" by dogmatic extremists in the real world may thus be manifested as a form of position-taking: proposing low-quality policies that are hopelessly extreme.

\section{Related Literature}

Our model provides a new approach to studying competition for intra- and inter-organizational influence. The key features that determine its empirical domain are (i) open competition, (ii) a significant common value element of policy preferences, and (iii) the potential for common value investments that are up-front and noncontractible, nontransferable across policies, and verifiable.

A now-vast literature considers the strategic properties of common value investments by experts in acquiring information about an unknown state of the world. The investments are typically modeled as noncontractible, nonverifiable, and pertaining to a common additive shift across a continuum of policies. Such models have been widely applied within political science to study the institutional determinants of high-quality policies (Gailmard and Patty 2012). They also feature information that is effectively transferable across policies, a property that Callander (2008) terms "invertibility" and criticizes for being unrealistic. Single-expert models typically deliver "ally principle" results in which a decision maker prefers to listen or delegate to someone who shares her policy preferences (e.g., Crawford and Sobel 1982, Bendor and Meirowitz 2004). Results from multi-expert models are more diverse (Gilligan and Krehbiel 1989, Battaglini 2002) but very sensitive to technical assumptions (Ambrus and Takahashi 2008). Another odd feature of competitive signaling models is that each expert benefits from the other expert's presence, due to the reduced variance of policy outcomes. In our policy development model, in contrast, each entrepreneur would prefer to be a monopolist rather than having to compete.

A growing literature studies noncontractible investments by single experts that are partially or fully nontransferable across policies, in settings both verifiable (Londregan 2000; Ting 2011; Hirsch and Shotts 2012) and nonverifiable (Aghion 
and Tirole 1997; Callander 2008). The inherent protection afforded by nontransferability has important strategic implications; experts attempt to exploit their monopoly power over investments to compel decision makers to accept policies that promote their interests. In these settings, an expert with divergent preferences is often preferable to one with aligned preferences, provided that there are institutional constraints on her use of informal agenda power (Hirsch and Shotts 2012, 2014a).

Another class of competitive models analyzes political influence via transfers (Groseclose and Snyder 1996; Dixit, Grossman, and Helpman 1997). Intrafirm competition is also analyzed by several authors, including Milgrom and Roberts (1988) and Lazear and Rosen (1981). Many of these models assume contractibility. Within political institutions, however, nominal principals typically have sharply limited means to control their subordinates (Moe 1984) and formal commitment is often impossible due to the lack of external enforcement. In some environments lacking formal contracts, repetition makes it possible to create informal relational ones (Baker, Gibbons, and Murphy 2002). However, this is less feasible in political environments, where many decision makers are short-lived (Heclo 1977).13 Moreover, as was the case in the early years of the New Deal, political leaders typically face a high degree of urgency to enact policy on a given issue-as noted in Kingdon's (1995) classic book, "policy windows" open only briefly. This urgency further undermines leaders' ability to pressure subordinates to develop better policy proposals. In our model, competition is such a disciplining device.

The idea that disagreement can be beneficial also appears in other models with very different microfoundations. Landier, Sraer, and Thesmar (2009) consider a model in which decision making and implementation are delegated by a firm owner to separate actors, whose biases can help counterbalance each other. Dewatripont and Tirole (1999) and Gul and Pesendorfer (2012) develop models in which competition provides incentives for actors to produce public or verifiable information to influence a decision. ${ }^{14}$

Finally, we note that variants of our model could be applied to other environments where actors propose policies and compete to have them enacted by exerting costly effort, e.g., lobbying (Epstein and Nitzan 2004; Jordan and Meirowitz 2012), valence competition in elections (Ashworth and Bueno de Mesquita 2009), and judicial opinion writing (Lax and Cameron 2007). In many such models, it would be natural to analyze the simultaneous choice of ideology and effort. However, to the best of our knowledge, previous research has focused on models in which actors choose ideological and nonideological offers sequentially, rather than analyzing them as two components simultaneously chosen in an all-pay contest.

\section{Conclusion}

We have presented a model of policy development in which factions have different ideologies or preferences, yet also agree on certain common objectives. Competing

\footnotetext{
${ }^{13}$ Most high-level political appointees in the US Federal Government stay for less than 18 months, and their subordinates are keenly aware of this fact.

${ }^{14}$ In these two models — unlike Crawford and Sobel (1982)—experts also don't care about the state, so its realization will align the decision maker's preference with one or the other's interests.
} 
policy developers can appeal to a decision maker by making productive, policy-specific investments to improve the quality of their proposals. Rather than being tailored narrowly to any specific institution, our model is designed to capture features of many different political organizations, including legislatures, parties, democratic polities, non-governmental organizations, militaries, and government agencies.

The key features of our model's empirical domain are that different actors can develop policies for consideration by a decision maker, and that policy consists of both a common values component and a component over which actors disagree. For example, the commissions in charge of some US government agencies have multiple members with different preferences, and even if a single decision maker like the board median is ultimately decisive, the other board members have the opportunity to develop policy proposals. Similarly, a wide range of interest groups are allowed to make policy suggestions in notice and comment procedures for regulatory rule-making. Our model suggests that these institutions promote beneficial policy development competition. It also suggests an explanation for the importance of programmatic parties in promoting effective governance in developing countries. ${ }^{15}$ Parties with strong policy preferences have an incentive to invest in quality in order to increase their chances of gaining control of the government. Because a crucial form of quality in developing countries is choosing noncorrupt candidates for office, our model suggests that countries with programmatic parties will exhibit lower levels of corruption when compared to countries where parties don't have firm policy objectives.

Our analysis suggests several avenues for future work. One possibility is to analyze policy entrepreneurs' choice about whether to use targeted benefits like pork or collective benefits like policy quality to acquire support for their proposals. Another possibility is to consider aspects of institutional design, including subsidies for policy development, endogenous selection of entrepreneurs, the addition of veto players, or the delegation of decision-making authority.

\section{REFERENCES}

Aghion, Philippe, and Jean Tirole. 1997. "Formal and Real Authority in Organizations." Journal of Political Economy 105 (1): 1-29.

Ambrus, Attila, and Satoru Takahashi. 2008. "Multi-Sender Cheap Talk with Restricted State Spaces." Theoretical Economics 3 (1): 1-27.

-Ashworth, Scott, and Ethan Bueno de Mesquita. 2009. "Elections with Platform and Valence Competition." Games and Economic Behavior 67 (1): 191-216.

- Baker, George, Robert Gibbons, and Kevin J. Murphy. 2002. "Relational Contracts and the Theory of the Firm.” Quarterly Journal of Economics 117 (1): 39-84.

-Battaglini, Marco. 2002. "Multiple Referrals and Multidimensional Cheap Talk." Econometrica 70 (4): 1379-1401.

Baye, Michael R., Dan Kovenock, and Casper G. de Vries. 1993. "Rigging the Lobbying Process: An Application of the All-Pay Auction." American Economic Review 83 (1): 289-94.

- Baye, Michael R., Dan Kovenock, and Casper G. de Vries. 2012. "Contests with Rank-Order Spillovers." Economic Theory 51 (2): 315-50.

Bendor, Jonathan B. 1985. Parallel Systems: Redundancy in Government. Berkeley, CA: University of California Press.

-Bendor, Jonathan, and Adam Meirowitz. 2004. "Spatial Models of Delegation." The American Political Science Review 98 (2): 293-310.

Callander, Steven. 2008. "A Theory of Policy Expertise." Quarterly Journal of Political Science 3 (2): $123-40$.

\footnotetext{
${ }^{15}$ We thank Georgy Egorov and Frederico Finan for suggesting this application of our model.
} 
Che, Yeon-Koo, and Ian L. Gale. 1998. "Caps on Political Lobbying.” American Economic Review 88 (3): 643-51.

-Che, Yeon-Koo, and Ian Gale. 2003. "Optimal Design of Research Contests." American Economic Review 93 (3): 646-71.

Crawford, Vincent P., and Joel Sobel. 1982. “Strategic Information Transmission.” Econometrica 50 (6): 1431-51.

Dewatripont, Mathias, and Jean Tirole. 1999. “Advocates.” Journal of Political Economy 107 (1): 1-39.

Dixit, Avinash, Gene M. Grossman, and Elhanan Helpman. 1997. "Common Agency and Coordination: General Theory and Application to Government Policy Making." Journal of Political Economy 105 (4): 752-69.

-Epstein, Gil S., and Shmuel Nitzan. 2004. "Strategic Restraint in Contests." European Economic Review 48 (1): 201-210.

-Esteban, Joan, and Debraj Ray. 1999. “Conflict and Distribution.” Journal of Economic Theory 87 (2): $379-415$.

Gailmard, Sean, and John W. Patty. 2012. "Formal Models of Bureaucracy." Annual Review of Political Science 15 (1): 353-77.

Gerlak, Andrea K., and Patrick J. McGovern. 1999. "The Twentieth Century: Progressivism, Prosperity, and Crisis.” In The Environmental Presidency, edited by Dennis L. Soden, 41-76. Albany, NY: SUNY Press.

Gilligan, Thomas W., and Keith Krehbiel. 1989. "Asymmetric Information and Legislative Rules with a Heterogeneous Committee.” American Journal of Political Science 33 (2): 459-90.

Groseclose, Tim, and James M. Snyder, Jr. 1996. "Buying Supermajorities." American Political Science Review 90 (2): 303-15.

Gul, Faruk, and Wolfgang Pesendorfer. 2012. "The War of Information.” Review of Economic Studies 79 (2): 707-34.

Heclo, Hugh. 1977. A Government of Strangers: Executive Politics in Washington. Washington, DC: Brookings Institution.

Hirsch, Alexander V., and Kenneth W. Shotts. 2012. "Policy-Specific Information and Informal Agenda Power." American Journal of Political Science 56 (1): 67-83.

Hirsch, Alexander V., and Kenneth W. Shotts. 2014a. "Policy-Development Monopolies: Adverse Consequences and Institutional Responses." http://people.hss.caltech.edu/ avhirsch/monopoliesforweb.pdf (accessed February 12, 2015).

Hirsch, Alexander V., and Kenneth W. Shotts. 2014b. "Policy Entrepreneurship with Veto Players." Unpublished.

Hitt, Matthew P., Craig Volden, and Alan E. Wiseman. 2014. "Spatial Models of Legislative Effectiveness." http://www.vanderbilt.edu/csdi/SpatialModelsofLegislativeEffectiveness.pdf (accessed February 12,2015$)$.

-Jordan, Stuart V., and Adam Meirowitz. 2012. "Lobbying and Discretion.” Economic Theory 49 (3): 683-702.

Kendall, Chad, Tommaso Nannicini, and Francesco Trebbi. 2015. "How Do Voters Respond to Information? Evidence From a Randomized Campaign.” American Economic Review 105 (1): 322-53.

Kingdon, John. 1995. Agendas, Alternatives, and Public Policies. 2nd ed. New York: Harper Collins.

Konrad, K. A. 2000. "Sabotage in Rent-Seeking Contests." Journal of Law, Economics, and Organization 16 (1): 155-65.

Krehbiel, Keith. 1998. Pivotal Politics: A Theory of US Lawmaking. Chicago: University of Chicago Press.

Landier, Augustin, David Sraer, and David Thesmar. 2009. “Optimal Dissent in Organizations.” Review of Economic Studies 76 (2): 761-94.

Lax, Jeffrey R., and Charles M. Cameron. 2007. "Bargaining and Opinion Assignment on the US Supreme Court.” Journal of Law, Economics, and Organization 23 (2): 276-302.

-Lazear, Edward P., and Sherwin Rosen. 1981. "Rank-Order Tournaments as Optimum Labor Contracts." Journal of Political Economy 89 (5): 841-64.

Leuchtenburg, William E. 1963. Franklin D. Roosevelt and the New Deal: 1932-1940. New York: Harper \& Row.

Londregan, John B. 2000. Legislative Institutions and Ideology in Chile. New York: Cambridge University Press.

Milgrom, Paul, and John Roberts. 1988. "An Economic Approach to Influence Activities in Organizations.” American Journal of Sociology 94 (S): S154-S179.

Moe, Terry M. 1984. “The New Economics of Organization.” American Journal of Political Science 28 (4): 739-77. 
Rotemberg, Julio J., and Garth Saloner. 1994. "Benefits of Narrow Business Strategies.” American Economic Review 84 (5): 1330-49.

Schlesinger, Arthur M, Jr. 1958. The Age of Roosevelt, Vol. II, 1933-1935: The Coming of the New Deal. New York: Houghton Mifflin.

-Siegel, Ron. 2009. “All-Pay Contests.” Econometrica 77 (1): 71-92.

-Snyder, James M. 1991. "On Buying Legislatures.” Economics and Politics 3 (2): 93-109.

Ting, Michael M. 2011. "Organizational Capacity.” Journal of Law, Economics, and Organization 27 (2): 245-71.

Triossi, Matteo, Patricio Valdivieso, and Benjamín Villena-Roldán. 2014. "A Spatial Model of Voting with Endogenous Proposals: Theory and Evidence from the Chilean Senate." Universidad de Chile CEA Working Paper 294.

Tullock, Gordon. 1980. “Efficient Rent Seeking.” In Toward a Theory of the Rent Seeking Society, edited by James M. Buchanan, Robert D. Tollison, and Gordon Tullock, 153-79. College Station, TX: Texas A\&M University Press.

Weber, Max. 1991. From Max Weber: Essays in Sociology. New York: Routledge. 